\title{
EFFECT OF CERVICAL RELINING OF ACRYLIC RESIN COPINGS ON THE ACCURACY OF STONE DIES OBTAINED USING A POLYETHER IMPRESSION MATERIAL
}

\author{
André Tomazini Gomes de SÁ ${ }^{1}$, César Antunes de FREITAS ${ }^{2}$, Fátima Cristina de $\mathrm{SÁ}^{3}$, Wagner José Silva URSI", \\ Tânia Christina SIMÕES ${ }^{5}$, Márcia Furtado Antunes de FREITAS ${ }^{6}$
}

\author{
1- DDS, MSc, Professor, Discipline of Restorative Dentistry, Londrina School of Dentistry, State University of Londrina, PR, Brazil. \\ 2- DDS, MSc, PhD, Assistant Professor, Discipline of Dental Materials, Bauru School of Dentistry, University of São Paulo, Bauru, SP, Brazil. \\ 3- DDS, MSc, PhD, Professor, Discipline of Restorative Dentistry, Londrina School of Dentistry, State University of Londrina, PR, Brazil. \\ 4- DDS, MSc, Professor, Discipline of Restorative Dentistry, Londrina School of Dentistry, State University of Londrina, PR, Brazil. \\ 5- DDS, Private Practice at Londrina - PR. \\ 6- DDS, Graduate Student in Dental Materials, Bauru School of Dentistry, University of São Paulo, Bauru, SP, Brazil.
}

Corresponding address: César Antunes de Freitas - Disciplina de Materiais Dentários, Faculdade de Odontologia de Bauru -USP. Alameda Dr. Octávio Pinheiro Brisolla, 9-75 - Vila Universitária - 17043-101 - Bauru - SP. e-mail: cfreitas@fob.usp.br

Received: October 16, 2006 - Modification: May 28, 2007 - Accepted: October 11, 2007

\begin{abstract}
$T_{\text {re }}$

he purpose of this study was to evaluate the accuracy of the respective dies after polyether elastomeric procedure in the presence or absence of cervical contact of the acrylic resin shell with the cervical region, establishing a comparison to dies obtained with stock trays. This study consisted of three groups with 10 specimens each: 1) acrylic copings without cervical contact, (cn); 2) acrylic copings with cervical contact (cc); 3) perforated stock tray, (st). The accuracy of the resulting dies was verified with the aid of a master crown, precisely fit to the master steel die. ANOVA test found statistically significant differences among groups $(\mathrm{p}<0.001)$. Tukey's test found that the smallest discrepancy occurred in group cn, followed by $\mathrm{cc}$, while the st group presented the highest difference ( $\mathrm{cc} x \mathrm{cn}$ : $\mathrm{p}=0.007$; st $\mathrm{x} \mathrm{cn:} \mathrm{p}<0.001$; st $\mathrm{x} \mathrm{cc:} \mathrm{p}<0.001$ ).
\end{abstract}

Uniterms: Elastomers. Dimensional accuracy. Dental impression materials. Acrylic resins.

\section{INTRODUCTION}

When a tooth is prepared to receive a full crown, the accuracy of the respective stone model is dependent on the properties of the impression material and on the impression techniques. Different scientific investigations have evaluated the impression material aspects, such as the setting characteristics ${ }^{20}$, hydrophilicity ${ }^{14,16,17,19,24}$, ability to record surface detail ${ }^{19,25}$, dimensional stability ${ }^{1,9,10,14,18,27}$ and adhesion to impression tray ${ }^{5,8}$. Other studies have been carried out to assess the influence of the tray type and impression material thickness on the accuracy of the impression or its resulting die.

Comparing the dimensional accuracy and stability of impressions made from custom acrylic resin and stock trays, Tjan, et al. ${ }^{26}$ (1992), Valderhaug, et al. ${ }^{27}$ (1984) and Bomberg, et $\mathrm{al}^{5}$ (1988) reported that the use of stock trays did not affect the dimensional accuracy and stability of the studied impression material. On the other hand, Lacy, et al. ${ }^{18}$ (1981), Boulton, et al. ${ }^{6}$ (1996) and Ciesco, et al. ${ }^{10}$ (1981) found evidence that impressions taken in custom-made acrylic trays minimize dimensional changes in molds and dies. Araújo and Jorgensen ${ }^{3}$ (1985) and Eames, et al. ${ }^{13}$ (1979) assessed to which degree the elastomer thickness, which varied between 1 to $4 \mathrm{~mm}$ and 2 to $6 \mathrm{~mm}$, respectively, inside stock and custom trays, affects accuracy and concluded that the increase in thickness produced greater distortion.

The use of a custom-made, acrylic resin coping, occasionally referred to as acrylic shel1 ${ }^{7,12,15}$, appears to be a more satisfactory alternative as the elastomeric material's thickness is diminished and uniform in all regions. Additionally, while relining the cervical area of an acrylic coping, contact is established between the acrylic and gingival termination of the prepared tooth. This procedure is done to displace the flow of the elastomer in the direction of the gingival crevice, affording a good reproduction of the finish line. Although the acrylic shell technique has a widespread use among clinicians, there is no information in the literature regarding a possible detrimental effect on the accuracy of the stone die caused by the contact between 
the acrylic shell and the prepared tooth.

The objective of the present study was to evaluate the accuracy of the respective dies after the use of a polyether impression material in the presence or absence of cervical contact of the acrylic resin shell with the dental surface, establishing a comparison to dies obtained with stock trays. The null hypothesis was that neither the type of tray nor the contact established between the acrylic shell and the tooth would interfere with the accuracy of the resulting dies.

\section{MATERIALAND METHODS}

All impressions, model fabrication and measurement of results were performed in a temperature $\left(23 \pm 1^{\circ} \mathrm{C}\right)$ and humidity $(50 \pm 5 \%)$ controlled environment. Study groups of 10 specimens each were thus established: 1 - Acrylic copings without cervical contact (cn); 2 - Acrylic copings with cervical contact (cc); 3 - Stock perforated tray (st).

The original structure used for the impressions consisted of a truncated stainless steel master die representing a fullcrown preparation with an $8 \mathrm{~mm}$ base diameter, $8 \mathrm{~mm}$ in height and a convergence angle of 5 degrees. The undercut cervical region was $1 \mathrm{~mm}$ in height ${ }^{3}$.

The steel master die was attached to a steel impression platform, through its moveable arm. At the base of the platform, various types of impression trays could be fastened. Either side of the base had a cylindrical vertical shaft. The moveable arm had two orifices which fit over the shafts and allowed the arm to slide along their full height. The desired height for the moveable arm was established by an adjustable spacer ring existing on one of the shafts.

A stainless steel ring, designated as the master crown, was also part of the assembly and was precisely fit to the master steel die. When the "occlusal" surface of the seated master crown was upward, the plane of the master die was at the same height as the plane of the master crown, as verified by a depth microscope (Carl Zeiss, Jena, Germany) at $\mathrm{x} 128$ magnification and $1 \mu \mathrm{m}$ accuracy.

A cast nickel-chromium coping, with a uniform thickness of $0.2 \mathrm{~mm}$, was used as a spacer. Twenty custom-made copings were fabricated with DuraLay Inlay Resin (Reliance Dental Mfg. Co., Worth, IL, USA) applied over the spacer coping using the Nealon brush technique ${ }^{22}$, thus establishing an uniform thickness reserved for the impression material within the acrylic coping. Each acrylic coping was attached with green stick modeling compound to a perforated plate which was locked on to the base of the impression platform. The acrylic coping's alignment in relation to the master die was achieved using the spacer coping that remained within the crown. The moveable arm was lifted from the platform and the spacer coping removed. No cervical contact existed between the master die and ten of the acrylic copings. For the ten remaining acrylic copings, a cervical band with an approximate vertical height of $2 \mathrm{~mm}$ was fabricated after the acrylic coping was positioned at the base of the impression platform. The two types of acrylic copings are illustrated: with no cervical contact (Figure 1A) and with cervical contact (Figure 1B).

The stock stainless-steel perforated trays had an internal diameter and height of $16 \mathrm{~mm}$. The thickness of the impression material was $4 \mathrm{~mm}$ in the area surrounding the greatest diameter and in the occlusal area of the master die. These trays were centered under the master die and the height established using an adjustable spacer ring.

The elastomeric impression material used for the impressions was Impregum F (3M ESPE, Dental Products, Seefeld, Germany: base paste lot $n^{\circ} 1670$; catalyst lot $n^{\circ}$ 3049). Prior to each impression, the master die was cleaned with a sponge soaked in a solution with equal parts of ethylic alcohol and sulphuric ether. This was followed by a coating of calcium stearate to prevent the elastomeric material from sticking to the metal of the master die. This coating was applied with a brush and the excess was blown off, leaving a quite thin and uniform layer, according the ANSI/ADA $\mathrm{n}^{\circ} 19$ specification ${ }^{2}$. As the calcium stearate was incorporated by the impression material, it does not caused discrepancy in the linear dimension of the master die.

An adhesive supplied by the manufacturer was applied on the internal side of the acrylic copings and $2 \mathrm{~mm}$ around the external gingival contour. The adhesive was allowed to air dry for 5 minutes. No adhesive was used in the stock trays, as the retention of the polyether impression material was afforded by its perforated holes.

A base/catalyst weight ratio of 7:1 (manufacturer's instruction) was used and verified with a Sauter precision scale (model D7470), on to which a sheet of mixing pool supplied by the manufacturer had been placed. For use with the acrylic coping the quantities were, respectively, $1.4 \mathrm{~g}$ and $0.2 \mathrm{~g}$, where as for the stock tray the quantities were 3.5 $\mathrm{g}$ and $0.5 \mathrm{~g}$. The two pastes were mixed using a $\mathrm{n}^{\circ} 24$ spatula for 45 seconds. A $5 \mathrm{~mL}$-plastic syringe was loaded with the homogenized paste then used to completely fill the stock tray or the acrylic coping, as well as to coat the cervical area of the master die. Immediately the moveable arm of the impression platform was placed over the shafts and lowered until seated upon the spacer ring on the shaft, and locked in place with a screw. The time elapsed between completion of mixing and the final seating of the master die in the impression material was 45 seconds. The platform was then immediately immersed in a water bath at $37 \pm 1^{\circ} \mathrm{C}$. The time allowed for complete polymerization of the polyether impression material was 10 minutes, beginning when the mobile arm was locked in place until the die was separated from the impression.

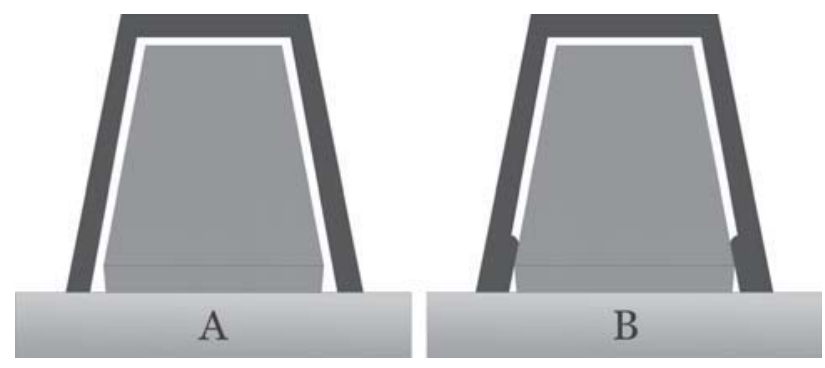

FIGURE 1- Schematic drawing of acrylic impression copings. 1A - acrylic coping without cervical contact; 1B acrylic coping with cervical contact 
A base was constructed on the dies for ease of handling. Once the excess material was eliminated, masking tape was placed around the acrylic copings prior to impression pouring. This procedure was unnecessary for the stock trays as the excess material already provided a circumferential wall.

Each Vel-Mix die (setting expansion of $0.10 \%$ at the liquid/ powder ratio of 0.2 according the manufacturer, Kerr, USA) was poured five minutes after the master die being removed from the impression. As much as $5 \mathrm{~g}$ of stone powder were mixed with $1 \mathrm{~mL}$ of deionized water in a rubber bowl over a vibrator for 1 minute. The mold and base were completely filled with stone using the same vibrator. One hour later, the stone die was removed from the impression and examined with a magnifying lens for any eventual defects. Small nodules were carefully removed with a Bard Parker blade. Seven days after fabrication, the dies were leveled by their occlusal plane using a leveling device and stabilized with modeling putty. Leveling was necessary in order to analyze the fit of the master crown to the die employing the depth microscope.

Measurements of the vertical distance (expressed in micrometers) between the occlusal surface of the stone die and the upper plane of the master crown seated upon it were made for each group. Each crown and die unit was measured in 4 regions (3, 6, 9, and 12 o'clock), 3 times each. The mean arithmetic value of these 12 readings was considered to be the degree of accuracy of the die. Positive or negative values indicate that the upper plane of the master crown was respectively higher or lower than the occlusal surface of the die.

One-way ANOVA was used to verify statistically significant differences among groups. Tukey's test (5\%) was used to verify which groups presented these differences. Significance level was set at 5\%

\section{RESULTS}

Means and standard deviations of vertical distances for each group are presented in Table 1. ANOVA found statistically significant differences among groups $(\mathrm{p}<0.001)$. Tukey's test found that the smallest discrepancy was seen

TABLE 1- Means, standard deviation (SD) and coefficient of variation $(\mathrm{CV})$ in depth measurement $\mathrm{s}(\mu \mathrm{m})$ for the tested groups

\begin{tabular}{llll}
\hline & \multicolumn{3}{c}{ Groups } \\
cn & cc & st \\
\hline Mean & 0.03 & 85.37 & 397.70 \\
SD & 35.32 & 67.92 & 62.56 \\
CV & 11.77 & 0.008 & 0.002 \\
\hline
\end{tabular}

$\mathrm{cn}=$ acrylic copings without cervical contact; $\mathrm{cc}=$ acrylic copings with cervical contact; st $=$ perforated stock tray. for group cn, followed by cc, while the st group presented the highest difference. A box-plot representation for each group is illustrated in Figure 2.

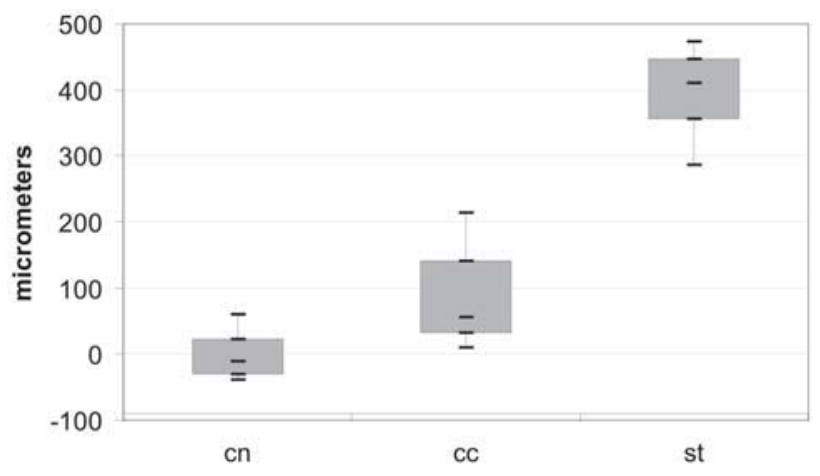

FIGURE 2- Box-plot of data expressed in $\mu \mathrm{m}$. cn - acrylic copings without cervical contact; cc - acrylic copings with cervical contact; st - stock perforated tray

\section{DISCUSSION}

This experiment demonstrates that the impression with the acrylic resin shell produced less dimensional distortion in the resulting dies than the perforated stock tray. Additionally, it revealed that the contact of the acrylic shell with the molded structure affected the accuracy of its dies. Thus, the null hypothesis was rejected.

The impression platform used for this study is similar to those used by Araújo and Jörgensen ${ }^{3}$ (1985), and it is not suitable for application on non-full crown preparations. The linear dimensional changes detected on the stone dies represent alterations which occurred along the impression process.

The dimensional accuracy of various types of impression materials has also been studied by comparing linear measurements between a group of points on one or more surfaces of a test model and the corresponding reference model $1^{5,6,10,11,13,18,23,26,27}$. Although valuable statistical information is gathered with the aforementioned type of study, the present method was chosen for being deemed more suitable for our objectives, having in mind, however, that it is not possible to qualify accurately all the distortions occurred in the die. As the dimensional alterations do not occur equally in all directions, the master crown's degree of fit is expressive only in regard to the magnitude of these distortions without inference to how they occurred.

It must be noted that the values observed in this procedure would be discrepant with results derived from a sequence in which a cast crown is created from a stone die poured in the impression material mold ${ }^{13}$. The cast crown affords the parameter for measurement on the original structure, reflecting conditions that mimic the clinical process. The procedures from which the statistical values were obtained in this study are actually the reverse of the clinical process. The master crown was formed from the master die, and then fitted on to the dies poured from the 
impression. The master crown is the parameter for verification.

According to McCabe and $\operatorname{Storer}^{20}$ (1980), the major factors affecting the dimensional change of non-undercut impressions are the thermal contraction, polymerization contraction and contraction due to the loss of volatiles. There has been disagreement regarding the temperatures reached by impression material during intra-oral impression taking ${ }^{4}$. Albeit, among the analyzed studies, the environmental temperature during polymerization varied between $21^{\circ} \mathrm{C}$ and $37^{\circ} \pm 2^{\circ} \mathrm{C}$. In the studies in which impression was warmed up, the most widely mean was the water bath with temperatures between $32^{\circ} \mathrm{C}$ to $37^{\circ}$ $\mathrm{C}^{3,8,10,13,23,25}$. With this procedure, it is unclear whether the distortion observed was due to thermal contraction or polymerization contraction. However, in the clinical impression procedure, heating of the impression material is followed by cooling once it is removed from the mouth. Therefore if a mold is not heated during the studies that investigate its dimensional accuracy, the resulting information will possibly have diminished application under clinical conditions.

The impression materials dimensional stability is directly related to the continued polymerization and to the loss of volatile components in some materials ${ }^{19}$, being therefore timedependent. Valderhaug and Floystrand ${ }^{27}$ (1984) did not detected dimensional alterations in a condensation reaction silicone and in a polyether, over a period of 24 hours. Lacy, et al. ${ }^{18}$ (1981) registered that a polyether, adhesively bonded to custom trays, showed improved stability over condensation silicones and polysulfide used in the same fashion. Ciesco, et al. ${ }^{10}$ (1981) concluded that all impression materials poured immediately, using a custom tray, demonstrated superior dimensional accuracy and stability in comparison to those tested without the custom tray as well as the polyether consistently yielded superior results with or without custom tray. This aspect was not evaluated here, as all molds were poured with stone die 5 minutes after separation from the master die. The objective of the present study was to assess the impression accuracy ratter than the impression stability. To avoid any distortion in the mold caused by shrinkage undergone during the acrylic polymerization, the acrylic copings were formed 48 hours before the impression procedure ${ }^{21}$.

If elastomeric impression materials tend to shrink in the impression tray during polymerization, it may be assumed that the negative image of the master die is enlarged, since the impression material adheres to the adhesive or is mechanically locked to the surface of the tray. Within the parameters of this study, it is not possible to affirm that the accuracy of the dies was affected by the two different types of impression trays. The discrepancy was probably due to the difference in the thickness of the elastomer inside of each tray, which corroborates with the results found by Araújo and Jorgensen ${ }^{3}$ (1985), and Eames, et al. ${ }^{13}$ (1979).

Cannistraci $^{7}$ described a new impression technique using an acrylic band tray or acrylic shell, which carried the rubber impression material to the gingival margin of the preparation.
The impression material recommended by the author was a rubber silicone because, although the polysulfide has advantages such as longer shelf life and greater dimensional stability, it presents an unpleasant odor and color, is difficult to mix and is rather messy to handle. Regardless of personal opinions, any of the currently available elastomers can be applied as long as there is a good adhesion to the coping ${ }^{5,6}$. However, in cases that present deep sulcus and greater undercuts, polysulfides should be considered as more appropriate due to their greater elasticity and rupture strength ${ }^{20}$. A polyether was used for this study as it possesses a balanced variety of properties ${ }^{20}$.

Less potential for soft tissue trauma, void-free impression of the prepared tooth and good precision are among the advantages of this technique ${ }^{12}$. Due to the proximity of the coping with the tooth preparation, contact can occur with the applied adhesive, particularly in the cervical region. The intensity of this contact occurs to the degree of the pressure exerted during the impression and whether or not stops have been placed on the adjacent teeth, when present. For this study, close fitting yet passive contact was established between the coping and the master die. The misfit for the group of acrylic copings with cervical contact (cc) may have been caused by irregularities present on the contact surface (detected under small magnification). It is likely that the material in contact with the master die during the impression was the adhesive, rather than the impression material. As adhesive is already dry, any disturb in its surface, caused by the contact with the tooth, will promote an unreliable record of the tooth surface. Though the concept that the tray should not contact the molded structure is commonly applied in edentulous mouth impression, it have been disregarded in acrylic coping impression technique.

\section{CONCLUSIONS}

According to results obtained in this study regarding linear dimensional changes of the resulting stone dies, it is possible to conclude that: 1 . Impression with the acrylic resin shell yielded the highest dimensional accuracy; 2 . The contact of the acrylic shell with the molded structure affected the accuracy of the resulting dies.

\section{ACKNOWLEDGEMENTS}

The authors would like to thank Michelle McMahan, DDS, for the English version of the manuscript and CNPq (protocol: 132148/2001-3) for supporting of this study. 


\section{REFERENCES}

1- Adabo GL, Zanarotti E, Fonseca RG, Cruz CA. Effect of disinfectant agents on dimensional stability of elastomeric impression materials. J Prosthet Dent. 1999;81(5):621-4.

2- American Dental Association. Council on Dental Materials and Devices. Specification $\mathrm{n}^{\circ} 19$ for non-aqueous elastomeric dental impression materials. J Amer Dent Ass. 1977;94(4):733-41.

3- Araújo PA, Jörgensen KD. Effect of material bulk and undercuts on the accuracy of impression materials. J Prosthet Dent. 1985;54(6):791-4.

4- Blomberg PAH, Mahmood S, Smales RJ, Makinson OF. Some parameters for testing deformation of elastomeric impression materials. Aust Dent J. 1992;37(4):271-6.

5- Bomberg TJ, Goldfogel MH, Hoffman W, Bomberg SE. Considerations for adhesion of impression materials to impression trays. J Prosthet Dent. 1988;60(6):681-4.

6- Boulton JL, Gage JP, Vincent PF, Basford KE. A laboratory study of dimensional changes for three elastomeric impression materials using custom and stock trays. Aust Dent J. 1996;41(6):398-404.

7- Cannistraci AJ. A new approach to impression taking for crown and bridge. Dent Clin North Am. 1965;9(6):33-42.

8- Chai JY, Jameson LM, Moser JB, Hesby RA. Adhesive properties of several impression material systems: Part I. J Prosthet Dent. $1991 ; 66(2): 201-9$

9- Chen SY, Liang WM, Chen FN. Factors affecting the accuracy of elastometric impression materials. J Dent. 2004;32(8):603-9.

10- Ciesco JN, Malone WF, Sandrik JL, Mazur B. Comparison of elastomeric impression materials used in fixed prosthodontics. J Prosthet Dent. 1981;45(1):89-94.

11 - Corso M, Abanomy A, Di Canzio J, Zurakowski D, Morgano SM. The effect of temperature changes on the dimensional stability of polyvinylsiloxane and polyether impression materials. J Prosthet Dent. 1998;79(6):626-31.

12- Dimashkieh MR, Morgano SM. A procedure for making fixed prosthodontic impressions with the use of preformed crown shells. J Prosthet Dent. 1995;73(1):95-6.

13-Eames WB, Sieweke JC, Wallace SW, Rogers LB. Elastomeric impression materials: effect of bulk on accuracy. J Prosthet Dent. 1979;41(3):304-7.

14- Endo T, Finger WJ. Dimensional accuracy of a new polyether impression material. Quintessence Int. 2006;37(1):47-51.

15- Hoffman JM. Nontraumatic final impressions for fixed partial dentures. J Prosthodont. 1992;(1):61-4.

16- Johnson GH, Lepe X, Aw TC. The effect of surface moisture on detail reproduction of elastomeric impressions. J Prosthet Dent. 2003;90(4):354-64

17- Kanehira M, Finger WJ, Endo T. Volatilization of components from and water absorption of polyether impressions. J Dent. 2006;34(2):134-8.

18- Lacy AM, Fukui H, Bellman T, Jendrensen MD. Time-dependen accuracy of elastomer impression materials. Part II: polyether polysulfides and polyvinylsiloxane. J Prosthet Dent. 1981;45(3):32933.
19- McCabe JF, Carrick TE. Recording surface detail on moist surfaces with elastomeric impression materials. Eur J Prosthodont Restor Dent. 2006;14(1):42-6

20-McCabe JF, Storer R. Elastomeric impression materials: the measurement of some properties relevant to clinical practice. $\mathrm{Br}$ Dent J. 1980;149(3):73-9.

21 - Mojon P, Oberholzer JP, Meyer JM, Belser UC. Polymerization shrinkage of index and pattern acrylic resins. J Prosthet Dent. 1990;64(6):684-8.

22 - Nealon FH, Sheakley HG. An extraoral pin technique. J Prosthet Dent. 1969;22(6):638-46.

23 - Piwowarczyk A, Ottl P, Buchler A, Lauer HC, Hoffmann A. In vitro study on the dimensional accuracy of selected materials for monophase elastic impression making. Int J Prosthodont. 2002;15(2):168-74

24-Rupp F, Axmann D, Jacobi A, Groten M, Geis-Gerstorfer J. Hydrophilicity of elastomeric non-aqueous impression materials during setting. Dent Mater. 2005;21(2):94-102.

25-Schelb E, Cavazos E, Kaiser DA, Troendle K. Compatibility of type IV dental stones with polyether impression materials. J Prosthet Dent. 1988;60(5):540-2.

26- Tjan AH, Nemetz H, Nguyen LT, Contino R. Effect of tray space on the accuracy of monophasic polyvinylsiloxane impressions. J Prosthet Dent. 1992;68(1):19-28

27- Valderhaug J, Flöystrand F. Dimensional stability of elastomeric impression materials in custom-made and stock trays. J Prosthet Dent. 1984;52(4):514-7. 